\title{
Comparison between Experimentally Determined Total, Saturated and Trans Fat Levels and Levels Reported on the Labels of Cookies and Bread sold in Brazil
}

\author{
Vanessa Martins Hissanaga-Himelstein ${ }^{1,2}$, Mateus Santaella Vivaz Oliveira', Bruna Maria Silveira², \\ David Alejandro González-Chica ${ }^{3}$, Rossana Pacheco da Costa Proença ${ }^{2,3, *}$, Jane Mara Block ${ }^{1,2}$ \\ ${ }^{1}$ Food Science Post Graduate Programa, UFSC (Federal University of Santa Catarina), Florianópolis-SC, Brazil \\ ${ }^{2}$ NUPPRE (Nutrition in Foodservice Research Nucleus), UFSC (Federal University of Santa Catarina), Florianópolis-SC, Brazil \\ ${ }^{3}$ Nutrition Post Graduate Programa, UFSC (Federal University of Santa Catarina), Florianópolis-SC, Brazil \\ *Corresponding author: rossana.costa@ufsc.br
}

Received October 07, 2014; Revised November 07, 2014; Accepted November 10, 2014

\begin{abstract}
In Brazil, the National Health Surveillance Agency (ANVISA) made the labeling of trans fats in foods mandatory from July 2006. The claim "trans fat free" can be used only for foods with trans fat content lower than $0.2 \mathrm{~g}$ and saturated fat content lower than $2 \mathrm{~g}$ per serving. This study determined fatty acid profile by gas chromatography and total fat content of nine cookie types and three bread types and the results obtained were compared with the values reported on the labels of these products. According to the results, $92 \%$ of the products contained trans fat, although only 33\% reported this on their labels. There was no significant difference with the experimentally determined levels of the products that reported the presence of trans fat. In $67 \%$ of the products that reported an absence of trans fat on their labels, less than $0.2 \mathrm{~g}$ of trans fat per serving was experimentally detected. The results revealed that the food product manufacturers studied are labeling trans fat content properly according to the law as they report products that have less than $0.2 \mathrm{~g}$ trans fat as "trans fat free". However, it bears noting that claiming that a product is free of trans fat on the label does not always guarantee that it is not present in the product and that the maximum suggested daily intake of $2 \mathrm{~g}$ will not be exceeded relatively easily considering that consumers do not always consume only the amount identified as the serving size on the label. Also, the paper enabled a discussion about the lack of standardization in the description of fat used as ingredient in foods.
\end{abstract}

Keywords: gas chromatography, hydrogenated vegetable oils, nutrition labeling, palm vegetable oil, trans fatty acids

Cite This Article: Vanessa Martins Hissanaga-Himelstein, Mateus Santaella Vivaz Oliveira, Bruna Maria Silveira, David Alejandro González-Chica, Rossana Pacheco da Costa Proença, and Jane Mara Block, "Comparison between Experimentally Determined Total, Saturated and Trans Fat Levels and Levels Reported on the Labels of Cookies and Bread sold in Brazil." Journal of Food and Nutrition Research, vol. 2, no. 12 (2014): 906-913. doi: 10.12691/jfnr-2-12-8.

\section{Introduction}

In the early twentieth century, the development of the hydrogenation process introduced industrially produced trans fat into the American diet. It use increased rapidly during the second half of the century as the food industry needed substitutes for animal fats due to their limited availability and high cost [1].

After the development of the hydrogenation process, hydrogenated vegetable oils began to be widely used by the food industry in confectionery and bakery products, cookies, pastries, ice cream, chocolate, fried foods, soup and margarine, among others. Incorporating this type of fat significantly improves the consistency, sensory characteristics and stability of these products $[2,3,4]$. It is estimated that $90 \%$ of the trans fat present in the Western diet is derived from the hydrogenation process [5].
Several studies have been published that associate trans fat intake with the development of cardiovascular disease $[6,7,8,9,10]$ and some types of cancer $[11,12,13]$ Cardiovascular disease in response to trans fat intake may be due to an increase in low density lipoprotein (LDL-c) levels along with a decrease in high density lipoprotein (HDL-c) levels [14].

Government regulatory agencies in Canada and the United States (Canadian Food Inspection Agency and Food and Drug Administration - FDA) mandated the reporting of the presence of these lipids on food labels in 2003. Foods labeled as "trans fat free" in Canada must contain less than $0.2 \mathrm{~g}$ of trans fat per serving and those in the United States must contain less than $0.5 \mathrm{~g}$ of trans fat per serving $[15,16]$.

In December 2003, the National Health Surveillance Agency (ANVISA) made the labeling of trans fats in foods mandatory from July 2006 on and the effective date was extended to July 2007. The legislation between the 
countries of Mercosur (Argentina, Brazil, Paraguay, and Uruguay) was harmonized. Since then, foodstuffs with trans fat content higher than $0.2 \mathrm{~g}$ per serving must have a warning about its trans fat content on the label. The claim "trans fat free" or " $0 \%$ trans fat" can be used only for foods with trans fat content lower than $0.2 \mathrm{~g}$ and saturated fat content lower than $2 \mathrm{~g}$ per serving [17]. A new legislation will be applied in 2014, when the producers will be allowed to label their products as "trans fat free" only when they present $0.1 \mathrm{~g}$ of trans fat per serving or less [18]. In November 2007, a technical cooperation agreement was established between the Ministry of Health, Brazilian Association of Food Industry (ABIA) and ANVISA. As part of that agreement, a forum entitled Healthy Eating Forum was created. Its objective was to find viable alternatives for the industry to replace and reduce the amount of trans fats, salt, and sugar in processed foods. The goal established in December 2008 was to reduce the trans fats levels in processed foods by the end of 2010, according to the limit recommended by The Pan American Health Organization (PAHO) and World Health Organization (WHO), which is no more than $5 \%$ trans fat in processed foods and no more than $2 \%$ of total fats in oils and margarines [19,20,21,22].

Studies comparing the reporting of trans fat on labels with experimentally determined trans fat presence show that claims of trans fat absence should be viewed with caution in Brazil and other countries. In many cases, products that highlight this absence can contain trans fat and the maximum recommended intake of $2 \mathrm{~g}$ per day can easily be reached. In addition, products with little or no trans fat often have high levels of saturated fat [1,23,24,25].

Foods such as cookies and bread form part of the Brazilian diet and their consumption has been rising in Brazil and worldwide [26,27].

In light of the importance of fat consumption to public health and product labeling, this study aimed to determine the fatty acid profile (with an emphasis on trans and saturated fats) of cookies and bread sold in Brazil and to compare them with the content reported on their labels. We also studied the names of oil/fat types in the ingredient lists, product prices and total fat content.

\section{Materials and Methods}

\subsection{Samples}

Nine cookie samples (three salt and water crackers, one milk cracker, two wafer cookies and three strawberryflavored cream-filled cookies) and three samples of sliced bread. The samples were collected in 2011 and the following information was obtained from the labels: serving size (g), trans fat content per serving (g), saturated fat content per serving (g), total fat content per serving (g), name of the added fatty raw material reported in the ingredients list, total package weight (g) and product price (in Brazilian reals).

\subsection{Total Fat Content}

The samples were homogenized and lyophilized. Lipid extraction was done to determine fat content according to methodology 933.05 of the AOAC [28].

\subsection{Fatty Acid Profile}

Fatty acid profile was determined by gas chromatography using a Varian CP-3800 gas chromatograph coupled with a Massas Varian Saturn 2200 (GC/MS/MS) spectrometer with an HP-88 chromatographic column of $60 \mathrm{~m}$, an external diameter of $0.25 \mathrm{~m}$ and $0,20 \mu \mathrm{m}$ of film thickness (Cyanopropilsiloxano). The analysis conditions were: injector $240^{\circ} \mathrm{C}$, Split of 100 constant; oven $\left(80^{\circ} \mathrm{C}\right.$ to $150^{\circ} \mathrm{C}, 5.0^{\circ} / \mathrm{min}, 150^{\circ} \mathrm{C}$ for $14 \mathrm{~min} ., 150^{\circ} \mathrm{C}$ to $220^{\circ}, 2^{\circ} / \mathrm{min}$. $220^{\circ} \mathrm{C}$ for $7 \mathrm{~min}$, total run time 70 minutes); MS (operating in automatic mode with mass range of 40 to 500 u.m.a. and filament current of $15 \mu \mathrm{A})$. The AccuStandards SFA006N - MethylTridecanoate pure was used as an internal standard. The samples were analysed in duplicate and the values presented correspond the averages of these values.

Lipid extraction was performed according to Folch et al. [29] and fatty acid methyl esters were obtained by the method described by Hartman and Lago [30].

\subsection{Statistical Analysis}

Individual information from each of the food products was used in the descriptive statistical analysis to identify the characteristics of each food in terms of fat content and price. The grouped values are presented as median and interquartile range and non-parametric tests were used in the analyses. The Wilcoxon test was applied for paired data to conduct an analysis comparing trans fat content with the results of the physical-chemical analysis.

The association between the fat content found in the physical-chemical analysis, the type of vegetable fat in the ingredients list (hydrogenated or not) and total fat content $(\leq 10 \mathrm{~g}$ or $>10 \mathrm{~g}$ of total fat) was assessed using the MannWhitney test. The Kruskal-Wallis test was used to assess the relationship with price per serving (in tertiles).

Fisher's exact test was used to compare the percentage of food products that exceeded the trans fat content permitted on labels to be considered "trans fat free" according to the legislation in effect during the data collection period $(0.2 \mathrm{~g} /$ serving), considering the type of fatty raw material reported in the ingredients list. A value of $p<0.05$ was considered indicative of statistical significance in all tests. Statistical analysis was done in the Stata v.11.0 statistical program (StataCorp, CollegeStation, TX, USA).

\section{Results and Discussion}

Table 1 shows the fatty acid profile results obtained from the samples studied.

Among saturated fatty acids, palmitic acid was the most commonly found (C16:0), followed by stearic acid (C18:0). The high presence of palmitic acid indicates the presence of palm oil, which justifies reporting vegetable fat on the labels of these food products.

Among unsaturated fatty acids, elaidic fatty acid (C18:1 $\Delta 9 \mathrm{t})$, which is mainly formed during vegetable oil hydrogenation [31], was found in nearly all food product samples. However, cream-filled cookie A, cream-filled cookie B and sliced bread C had only 0.03g, 0.09g and $0.01 \mathrm{~g}$ per $100 \mathrm{~g}$ respectively-i.e. reduced amounts of trans fat. On the other hand, wafer cookie A and wafer cookie B had larger amounts-i.e. 9.84g and 5.8g of elaidic acid per $100 \mathrm{~g}$ of product, respectively. 
Table 1. Fatty acids profile $(\mathrm{g} / \mathbf{1 0 0 g})$ of food products analyzed experimentally

\begin{tabular}{|c|c|c|c|c|c|c|c|c|c|c|c|c|}
\hline \multirow[t]{2}{*}{ Fatty acid } & \multicolumn{12}{|c|}{ Food products* } \\
\hline & 1 & 2 & 3 & 4 & 5 & 6 & 7 & 8 & 9 & 10 & 11 & 12 \\
\hline C8:0 & - & 0,01 & 0,06 & - & - & 0,02 & 0,02 & - & - & - & - & - \\
\hline C10:0 & - & 0,01 & 0,06 & - & - & 0,02 & 0,03 & - & - & - & - & - \\
\hline $\mathrm{C} 12: 0$ & 0,04 & 0,10 & 1,01 & 0,01 & 0,07 & 0,29 & 0,47 & 0,02 & - & - & - & - \\
\hline $\mathrm{C} 13: 0$ & - & - & - & - & - & - & - & - & - & - & - & - \\
\hline C14:0 & 0,03 & 0,14 & 0,45 & 0,05 & 0,04 & 0,14 & 0,32 & - & 0,05 & 0,02 & - & - \\
\hline C15:0 & - & - & - & - & - & - & 0,01 & - & - & - & - & - \\
\hline $\mathrm{C} 16: 0$ & 1,04 & 3,87 & 3,64 & 3,2 & 2,88 & 3,41 & 5,11 & 1,20 & 1,88 & 0,32 & 0,20 & 0,04 \\
\hline C17:0 & 0,01 & 0,01 & 0,02 & 0,01 & 0,02 & - & 0,01 & 0,01 & 0,01 & - & - & - \\
\hline C18:0 & 0,81 & 2,1 & 5,11 & 1,64 & 3,80 & 2,53 & 1,19 & 0,81 & 0,32 & 0,17 & 0,06 & 0,02 \\
\hline C20:0 & 0,02 & 0,03 & 0,06 & 0,05 & 0,11 & 0,06 & 0,05 & 0,02 & 0,01 & - & - & - \\
\hline C22:0 & - & - & 0,01 & - & - & - & - & - & - & - & - & - \\
\hline Saturated & 1,95 & 6,27 & 10,42 & 4,96 & 6,92 & 6,47 & 7,21 & 2,06 & 2,27 & 0,51 & 0,26 & 0,06 \\
\hline $\mathrm{C} 16: 1 \Delta 9$ & 0,01 & 0,05 & - & 0,02 & 0,01 & - & 0,03 & 0,01 & 0,03 & 0,01 & - & - \\
\hline $\mathrm{C} 18: 1 \Delta 9 \mathrm{t}$ & 2,13 & 0,03 & 0,09 & 0,3 & 9,84 & 5,8 & 0,2 & 2,93 & 0,20 & 0,1 & - & 0,01 \\
\hline $\mathrm{C} 18: 1 \Delta 9$ & 2,78 & 2,8 & 3,63 & 8,14 & 8,73 & 7,54 & 3,78 & 3,24 & 1,53 & 0,44 & 0,22 & 0,07 \\
\hline $\mathrm{C} 18: 1 \Delta 11 \mathrm{t}$ & 0,21 & 0,10 & 0,14 & 0,3 & 0,92 & 0,58 & 0,1 & 0,35 & 0,05 & 0,02 & - & - \\
\hline $\mathrm{C} 20: 1 \Delta 9$ & - & 0,01 & 0,01 & 0,09 & 0,03 & 0,02 & 0,03 & 0,01 & - & - & - & - \\
\hline Monounsaturated & 5,13 & 2,99 & 3,87 & 8,85 & 19,53 & 13,94 & 4,14 & 6,54 & 1,81 & 0,57 & 0,22 & 0,08 \\
\hline Trans isomers & 2,34 & 0,13 & 0,23 & 0,60 & 10,76 & 6,38 & 0,30 & 3,28 & 0,25 & 0,12 & - & 0,01 \\
\hline $\mathrm{C} 18: 2 \Delta 6$ & 1,13 & 7,19 & - & - & 0,29 & 0,28 & 0,01 & 0,1 & - & - & - & - \\
\hline $\mathrm{C} 18: 2 \Delta 9$ & - & - & 5,38 & 3,69 & 0,53 & 2,31 & 3,75 & 1,28 & 4,53 & 0,47 & 0,15 & 0,1 \\
\hline $\mathrm{C} 18: 3 \Delta 9$ & 0,05 & 0,04 & 0,51 & 0,69 & 0,03 & 0,04 & 0,1 & 0,14 & 0,04 & 0,02 & 0,01 & - \\
\hline Polyunsaturated & 1,18 & 7,23 & 5,89 & 4,38 & 0,85 & 2,63 & 3,86 & 1,52 & 4,57 & 0,49 & 0,16 & $\mathbf{0 , 1}$ \\
\hline
\end{tabular}

*1- milk cracker; 2- cream filled cookie A; 3- cream filled cookie B; 4- cream filled cookie C; 5- wafer cookie A; 6- wafer cookie B; 7- water and salt cracker A; 8- water and salt cracker B; 9- water and salt cracker C; 10- sliced bread A; 11- sliced bread B; 12- sliced bread C.

This study's results agree with the findings of Norhayati et al., in which the Malaysian authors evaluated twelve cookie samples (eight domestic and four imported) and found considerably low amounts of trans fat due to the use of palm oil as an ingredient [32].

In contrast, Martin et al. evaluated twelve samples of cream crackers and found large amounts of trans fat. However, it should be noted that this study was conducted before mandatory trans fat labeling went into effect in Brazil [33].

A study published by Huang et al. also showed a high presence of trans fat in food products, including cookies. The authors concluded that trans fat was commonly found in foods sold in an African-American community in the United States [34].

Camp et al. assessed the impact of mandatory trans fat labeling in the United States. The authors concluded that the law contributed to reducing the use of hydrogenated vegetable oils in snack products. However, the replacement of this raw material led to an increase in the proportion of saturated fat in these products [25].

Similar results were found by Meremäe et al., who studied 26 fats available in the Estonian market in 2011. They found significantly reduced trans fat levels compared to the results they obtained in 2008-2009, with a parallel increase in saturated fat in these products [35].

The use of palm oil is noteworthy because, although it does not contain trans fat, it contains saturated fat, which is also associated with cardiovascular disease development ([36,37]). The extensive use of palm oil in bakery products may result from the difficulty of finding a technically appropriate replacement for hydrogenated vegetable oil [38].

Skeaf suggests the following transition to eliminate trans fat in food products: 1- go from hydrogenated vegetable oil (traditional practice) to palm oil; 2- go from palm oil to vegetable fat mixtures with high saturated fat content (current practice); and finally 3- go from vegetable fat with saturated fat to vegetable oils rich in oleic fatty acid without trans or saturated fat (future practice) [39].

The Food and Drug Administration (FDA) in the United States of America, concerned about the delay in the final elimination of trans fat in food products, preliminarily announced that the partially hydrogenated vegetable oil "should not be recognized as safe" for use in foods. If this decision becomes permanent, the industrially produced trans fat will eventually be eliminated from food in the country $[40,42]$.

The use of unsaturated vegetable oils to replace hydrogenated vegetable oils is supported by the World Health Organization (WHO), which, during the $66^{\text {th }}$ World Health Assembly in 2013, pointed to this strategy as being necessary to prevent and control communicable diseases in the 2013-2020 period [43].

Table 2 shows the types of fatty raw material used in the products studied as well as trans, saturated and total fat content (g/serving and g/100g) — both the experimentally determined values and the values reported on labels.

Reporting of the presence of trans fat per serving on nutritional labels occurred in $33 \%$ of the food products and was more frequent among the products that reported containing hydrogenated vegetable oil (75\%) than among those that did not specify the type of vegetable fat used-a statistically insignificant difference $(\mathrm{P}=0.24$ according to the Fisher exact test).

According to the analysis results, $42 \%$ of the samples contained considerable amounts of trans fat (values greater than $0.1 \mathrm{~g} /$ serving) while $50 \%$ had only small amounts of the isomer (values less than $0.1 \mathrm{~g} / \mathrm{serving}$ ). The products that were declared "trans fat free" on their labels were found to have less than $0.2 \mathrm{~g} / \mathrm{serving}$ in the laboratory analyses - the value under which RDC 360 permits the food industry to label its products as "trans fat free" [17]. For these foods, the terms "vegetable fat" or "hydrogenated vegetable oil” were cited in the ingredients lists. 
Table 2. Type of fat used, content of trans fatty acids and saturated fat (g/serving), experimentally determined and declared on the label, and price per serving of the products studied

\begin{tabular}{|c|c|c|c|c|c|c|c|c|c|}
\hline $\begin{array}{c}\text { Food } \\
\text { product }\end{array}$ & $\begin{array}{l}\text { Serving } \\
\text { (g) }\end{array}$ & $\begin{array}{l}\text { Declared } \\
\text { type of fat } \\
\text { in the } \\
\text { ingredients } \\
\quad \text { list } \\
\end{array}$ & $\begin{array}{c}\text { Trans fat } \\
\text { content } \\
\text { declared on } \\
\text { the label } \\
\text { (g/serving*) } \\
\end{array}$ & $\begin{array}{c}\text { Trans fat } \\
\text { content } \\
\text { determined } \\
\text { experimentally } \\
\text { (g/serving*) }\end{array}$ & $\begin{array}{c}\text { Saturated } \\
\text { fat content } \\
\text { declared on } \\
\text { the label } \\
\text { (g/serving*) }\end{array}$ & $\begin{array}{c}\text { Saturated fat } \\
\text { content } \\
\text { determined } \\
\text { experimentally } \\
\text { (g/serving*) }\end{array}$ & $\begin{array}{c}\text { Total fat } \\
\text { content } \\
\text { declared } \\
\text { on the } \\
\text { label } \\
(\mathrm{g} / 100 \mathrm{~g}) \\
\end{array}$ & $\begin{array}{c}\begin{array}{c}\text { Total fat } \\
\text { content } \\
\text { determined } \\
\text { experimentally } \\
(\mathrm{g} / \mathbf{1 0 0 g})\end{array} \\
\end{array}$ & $\begin{array}{c}\text { Price } \\
\text { per } \\
\text { serving } \\
\text { (US\$) }\end{array}$ \\
\hline $\begin{array}{c}\text { Milk } \\
\text { cracker }\end{array}$ & 30 & $\begin{array}{l}\text { Hydrogenated } \\
\text { vegetable oil }\end{array}$ & 0,50 & 0,70 & 0,70 & 0,58 & 9,80 & 10,50 & 0,26 \\
\hline $\begin{array}{c}\text { Cream } \\
\text { filled } \\
\text { cracker A }\end{array}$ & 30 & Vegetable fat & 0,00 & 0,04 & 2,40 & 1,88 & 18,66 & 17,60 & 0,60 \\
\hline $\begin{array}{l}\text { Cream } \\
\text { filled } \\
\text { cracker B }\end{array}$ & 30 & Vegetable fat & 0,00 & 0,07 & 2,80 & 3,13 & 20,66 & 21,50 & 0,56 \\
\hline $\begin{array}{c}\text { Cream } \\
\text { filled } \\
\text { cracker C }\end{array}$ & 30 & $\begin{array}{l}\text { Hydrogenated } \\
\text { vegetable oil }\end{array}$ & 0,00 & 0,18 & 3,60 & 1,49 & 20,00 & 19,40 & 0,70 \\
\hline $\begin{array}{c}\text { Wafer } \\
\text { cookie A }\end{array}$ & 30 & $\begin{array}{l}\text { Hydrogenated } \\
\text { vegetable oil }\end{array}$ & 3,60 & 3,22 & 1,50 & 2,08 & 29,33 & 30,20 & 0,36 \\
\hline $\begin{array}{l}\text { Wafer } \\
\text { cookie B }\end{array}$ & 30 & Vegetable fat & 2,00 & 1,91 & 1,86 & 1,94 & 28,30 & 25,20 & 0,34 \\
\hline $\begin{array}{c}\text { Salt and } \\
\text { water } \\
\text { cracker A }\end{array}$ & 30 & Vegetable fat & 0,00 & 0,09 & 2,50 & 2,16 & 15,00 & 16,20 & 0,48 \\
\hline $\begin{array}{c}\text { Salt and } \\
\text { water } \\
\text { cracker B }\end{array}$ & 30 & $\begin{array}{l}\text { Hydrogenated } \\
\text { vegetable oil }\end{array}$ & 0,80 & 0,98 & 1,16 & 0,62 & 14,00 & 11,10 & 0,32 \\
\hline $\begin{array}{l}\text { Salt and } \\
\text { water } \\
\text { cracker C }\end{array}$ & 30 & Vegetable fat & 0,00 & 0,08 & 1,39 & 0,68 & 10,66 & 9,00 & 0,60 \\
\hline $\begin{array}{c}\text { Sliced } \\
\text { bread A }\end{array}$ & 50 & Vegetable fat & 0,00 & 0,06 & 0,16 & 0,25 & 2,60 & 1,90 & 0,62 \\
\hline $\begin{array}{c}\text { Sliced } \\
\text { bread B }\end{array}$ & 50 & Palm oil & 0,00 & 0,00 & 0,13 & 0,13 & 0,80 & 0,80 & 0,58 \\
\hline $\begin{array}{c}\text { Sliced } \\
\text { bread C }\end{array}$ & 50 & $\begin{array}{l}\text { Hydrogenated } \\
\text { vegetable oil }\end{array}$ & 0,00 & 0,01 & 0,13 & 0,03 & 0,80 & 0,30 & 0,54 \\
\hline
\end{tabular}

According to a new Brazilian law that went into effect in 2014 [18], only foods with a trans fat content of $0.1 \mathrm{~g}$ per serving or less are permitted to be advertised as "trans fat free”. Although this study's data collection was done before this date, we highlight the example of cream-filled cookie C (0.18g of trans fat per serving), which did not have to report containing trans fat under the previous law and could claim to be "trans fat free". However, the product can no longer make this claim under the current law. This example helps to illustrate how the new law can indirectly contribute to reducing trans fat content in Brazilian food products.

All of the bread samples claimed to be "trans fat free" on their labels and this was confirmed experimentally through the results obtained, in which sliced breads A and $C$ had trace amounts of the isomer $(0.06 \mathrm{~g} / \mathrm{serving}$ and $0.01 \mathrm{~g} /$ serving, respectively) and sliced bread B had $0 \mathrm{~g}$ of trans fat per serving.

Among the twelve products analyzed, only sliced bread B's label specified the type of vegetable fat used as being palm oil. For five samples (42\%- four cookie samples and one bread sample) "hydrogenated vegetable oil" was reported, confirming that they contained trans fat. On the other hand, six samples (50\% -five cookie samples and one bread sample) reported containing "vegetable fat" and, considering the palmitic acid content of these products (between 14\% and 32\% of total fatty acids), the vegetable fat used was palm oil. In the last case, therefore, the manufacturers preferred to use the generic name "vegetable fat" instead of reporting the oil's origin-that is, to report "palm vegetable oil".
The physical-chemical analysis showed no relationship pattern between the samples' trans fat content and their saturated and total fat content. The breads had low amounts of trans, saturated and total fat. The cookies (such as cream-filled cookie B) had low trans fat content and high saturated and total fat content, in contrast to the milk cracker, which had low saturated fat content and high trans and total fat content.

Among the food products analyzed that reported vegetable fat in their ingredients lists, only one (wafer cookie B) had trans fat content greater than $0.1 \mathrm{~g}$ per serving (1.91g). The other food products had small amounts that ranged from $0.04 \mathrm{~g}$ to $0.09 \mathrm{~g}$ per serving. The products that reported containing hydrogenated vegetable oil generally had higher trans fat content, ranging from $0.01 \mathrm{~g}$ to $3.22 \mathrm{~g}$ per serving.

It is worth noting the trans fat content found in wafer cookie A (3.22g per serving). The value represents 160\% of the daily trans fat intake recommended by the Food Guide for the Brazilian Population ${ }^{[44]}$ in just one serving (30g). In this context, this study's findings suggest that, although most of the food products analyzed had small amounts of trans fat per serving, this situation is not uniform. In other words, some products in the Brazilian market still have high trans fat levels, contradicting the WHO [45], which recommends excluding this isomer from the human diet.

In terms of price per serving, the milk cracker, wafer cookies A and B and water and salt cracker B, which contained more than $0.2 \mathrm{~g}$ of trans fat per serving, had the lowest cost (less than US\$0.40 per serving). The other 
products had a similar price range (US\$0.48 to US\$0.70 per serving). Sliced bread $B$, which did not contain trans fat and reported "palm vegetable oil" in its composition, had an intermediate price in relation to the others.

The median trans fat content per serving reported on nutrition labels (0.00; range 0-3.6) was less than that of the physical-chemical analysis (median 0.08; range 0-3.2). However, this difference is statistically insignificant, as shown in Figure 1.

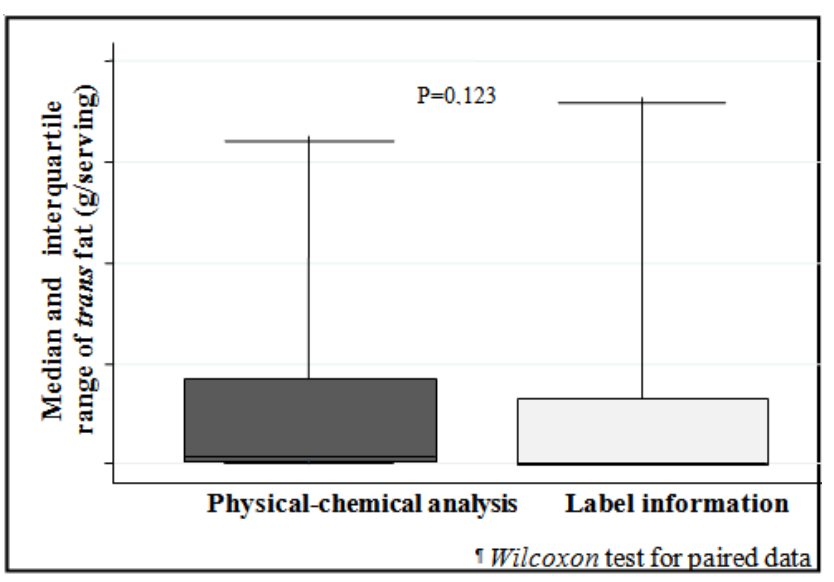

Figure 1. Content of trans fat per serving, identified in physicalchemical analysis and notified in nutrition labeling

Table 3 shows the association between the food product characteristics (name of the fatty raw material in the ingredients list, total fat content and price per serving) and trans fat content per serving according to the physicalchemical analysis.

Table 3. Relationship between content of trans fat per serving (g) identified in the physical-chemical analysis with the characteristics of food products

\begin{tabular}{|c|c|c|c|}
\hline \multirow{2}{*}{$\begin{array}{l}\text { Characteristics of food } \\
\text { products }\end{array}$} & \multicolumn{3}{|c|}{$\begin{array}{l}\text { Content of trans fat per serving (g) of the } \\
\text { food product determined experimentally }\end{array}$} \\
\hline & $\mathbf{N}$ & Median (Range) & p-value \\
\hline \multicolumn{4}{|l|}{ Ingredients list } \\
\hline Vegetable fat & 6 & $0,07(0,04-1,91)$ & \multirow[t]{2}{*}{$0,273^{\mathbb{\pi}}$} \\
\hline $\begin{array}{l}\text { Hydrogenated vegetable } \\
\text { oil }\end{array}$ & 5 & $0,70(0,01-3,23)$ & \\
\hline \multicolumn{4}{|l|}{ Total fat content $/ 100 \mathrm{~g}$} \\
\hline$\leq 10 \mathrm{~g}$ & 4 & $0,03(0,00-0,08)$ & \multirow{2}{*}{$0,027^{\natural}$} \\
\hline$>10 \mathrm{~g}$ & 8 & $0,44(0,04-3,23)$ & \\
\hline \multicolumn{4}{|l|}{$\begin{array}{c}\text { Price per serving (g) } \\
\text { (US\$) }\end{array}$} \\
\hline Tertile $1(0,26-0,36)$ & 4 & $1,45(0,70-3,23)$ & \multirow{3}{*}{$0,021 *$} \\
\hline Tertile $2(0,37-0,59)$ & 4 & $0,04(0,00-0,09)$ & \\
\hline Tertile $3(0,60-0,70)$ & 4 & $0,07(0,04-0,18)$ & \\
\hline
\end{tabular}

\section{"Mann-Whitney}

*Kruskal-Wall.

The products with higher total fat content $(>10 \mathrm{~g} / 100 \mathrm{~g}$ of product) also had higher trans fat content according to the physical-chemical analysis $(\mathrm{P}=0.027)$ compared to those that had lower total fat content $(<10 \mathrm{~g} / 100 \mathrm{~g}$ of product).

This result contradicts the hypothesis discussed by authors such as Camp et al. [25] that reducing trans fat content could lead to an increase in saturated and total fat content. It is suggested that this finding may indicate limitations in the total or partial replacement of hydrogenated vegetable oil when the food product requires higher fat content in its composition. This factor may be associated with the difficulties found in obtaining an appropriate fat substitute for bakery products as well as the potentially limited availability of substitutes in the market [46].

The food products with the lowest cost (first tertile) had the highest trans fat content, showing a statistically significant association.

The price factor appears to influence trans fat content, as shown in a Brazilian study by Silveira et al. The study analyzed the nutrition labels of 694 food products commonly consumed by children and adolescents in two retail establishments for consumers with distinct economic profiles and assessed whether price and affordability could be determined by trans fat content. The results indicated that the less affluent region had lower availability of products without trans fat. In addition, these products had higher prices compared to products that contained trans fat [47].

This relationship was also established in a study conducted by Galdino et al., which evaluated cream-filled cookies sold in Brazil [48]. In addition, a study that described the relationship between diet quality and cost in the United States found that diets higher in energy, sugar and fat content were lower in cost [49]. Donkin et al. [50] found that people of low socio-economic status generally had diets with high levels of these nutrients. Drewnoswski believes that this fact is due to the ease of producing, processing, transporting and storing such foods [51].

All of the food products analyzed in this study presented a serving size to report their nutritional information, as recommended by Brazilian law (30g for cookies and 50g for breads) [52]. Also, the trans fat content reported on the labels analyzed can be considered to be in proper compliance with the law in light of the content detected in the analysis. Thus, although the physical-chemical analysis showed that $92 \%$ of the food products had minimal or considerable amounts of trans fat, those that reported an absence of this type of fat (67\%) cannot be considered to be in violation of current law, which stipulates that foods containing less than $0.2 \mathrm{~g}$ of trans fat per serving can be labeled at "trans fat free" [17].

In an analysis of labels on Brazilian food products claiming to be "trans fat free", Aued-Pimentel et al. found $18 \%$ inconsistency between what was reported on the labels and what was found in the physical-chemical analysis. Such products had amounts of trans fat ranging from $0.3 \mathrm{~g}$ to $1.8 \mathrm{~g}$ per serving and it was observed that all products that listed "vegetable fat" as an ingredient (50\%) had trans fat levels higher than $0.2 \mathrm{~g} /$ serving in their composition. This finding shows that, although not specifically mentioned, vegetable fat reported on labels may be hydrogenated [53].

Therefore, the non-specific naming of ingredients used can compromise the nutrition information reported to consumers, as was discussed by Proença and Silveira. Reading "vegetable fat" in the ingredients list and not seeing trans fat in the nutritional information can lead consumers to believe that they will not be consuming trans fat [54]. Thus, this fact may amount to an infraction of the Consumer Defense Code [55], which establishes the consumer's right to be clearly informed of the characteristics of purchased and consumed products.

Silveira et al. analyzed the labels of 2,327 food products sold in Brazil and identified 14 different names 
for the component with trans fat that was identified as being hydrogenated and nine different names for the component with trans fat where it was unclear whether it was hydrogenated or not. Thus, it can be seen that uncertainty about the presence of trans fat in a product can persist even after consumers read the product label information [56]. Danish documents also raise the issue of ingredient names that leave unclear whether or not a vegetable fat is hydrogenated [57].

Howlett et al. reported that a lack of knowledge about trans fat and misinterpretation of its content on nutrition labels can lead to false conclusions. They emphasized that, in order for consumers to identify which foods are free of trans fat, they must have access to nutritional information and ingredients lists as well as the knowledge to interpret and question them [58].

Although this study's results are in accordance with Brazilian law, it bears noting that people often consume food products in amounts exceeding the serving sizes suggested on labels. For example, if a person consumes 15 units in a package of "trans fat free" cookies that have $0.19 \mathrm{~g}$ of the isomer in a serving of $2 \frac{1}{2} \mathrm{units}(30 \mathrm{~g})$, his/her consumption will be $1.14 \mathrm{~g}$ of trans fat. Since this amount exceeds one-half of $2 \mathrm{~g}$ /day, which is the maximum intake suggested by the Food Guide for the Brazilian Population [44], one can deduce that it is not difficult to exceed this maximum daily intake.

One may cite the small number of samples $(n=12)$ as a limitation of this study. However, it is worth noting that the samples collected represent bread and cookie brands that are widely consumed in Brazil. Furthermore, we selected products with different prices with the aim of representing the purchasing choices available to Brazilian consumers of different social strata.

Additionally, it is noteworthy that these breads and cookies are foods that are commonly present in the Brazilian diet [26]. These foods are also cited as some of the main trans fat sources in the diet $[59,60]$. In this context, analyzing these foods can enable not only the inference of trans fat intake from Brazilian breads and cookies but also form the basis of a discussion about reducing the isomer in these products.

This study has many strengths. First, it compares the information reported on bread and cookie labels with the trans, saturated and total fat values found in laboratory analyses. Although other studies have assessed fat content in foods, few have compared these values with the information on labels. Second, the laboratory analysis results enable a discussion about current Brazilian food labeling law, emphasizing the limit of trans fat allowed for a product to be labeled "trans fat free", as well as the lack of standardization in describing the oils used as product ingredients. Third, the data obtained in this study allowed us to assess the Brazilian food industry's performance in relation to food labeling law.

\section{Conclusion}

The results revealed that the food product manufacturers studied are labeling trans fat content properly according to the law as they report products that have less than $0.2 \mathrm{~g}$ of this isomer as "trans fat free". Nevertheless, it bears noting that claiming that a product is free of trans fat on the label does not always guarantee that it is not present in the product and that the maximum suggested daily intake of $2 \mathrm{~g}$ will not be exceeded relatively easily considering that consumers do not always consume only the amount identified as the serving size on the label.

The diversity of terms used for fat ingredients can confuse consumers as to whether or not a food product contains trans fat. For example, using the generic term "vegetable fat" does not clarify whether the oil is totally or partially hydrogenated, interesterified, fractionated or an unprocessed palm oil. In this context, it is recommended that the law be revised in order to standardize the names of the oils used. It is also suggested that the oil's origin (palm, soybean, corn, etc.) and manufacturing process (unprocessed, partially hydrogenated, interesterified, etc.) be described on food labels.

The use of different ingredients and oil types in the same products (e.g. breads) can indicate possible reformulations using alternative oils that do not have trans fat. Thus, it is suggested that the food industry continue investing in the development of trans fat free products as much as possible without increasing saturated fat content.

\section{Acknowledgement}

We acknowledge the financial support and Industrial Technology Development scholarships conferred by the CNPq under the 2009 SESI/Senai Innovation Announcement in partnership with the Industry Service of Santa Catarina.

\section{Competing Interests}

The authors have no competing interests.

\section{References}

[1] Remig, V., Franklin, B., Margolis, S., Kostas, G., Nece, T. and Street, J.C. "Trans Fats in America: A Review of Their Use, Consumption, Health Implications, and Regulation”. J Am Diet Assoc. 110 (4). 585-592. 2010.

[2] Eckel, R.H., Borra, S., Lichtenstein, A.H. and Yin-Piazza, S.Y. "Understanding the complexity of trans fatty acid reduction in the American diet”. Circulation. 115. 2231-2246. 2007.

[3] Wassel, P. and Young, N.W.G. "Food applications of trans fatty acid substitutes”. Int J Food Sci Tech. 42(5). 503-517. 2007.

[4] Fu, H., Yang, L., Yuan, H., Rao, P. and Lo, Y.M. "Assessment of trans fatty acids content in popular Western-style products in China”. J Food Sci. 73(8). S383-91. 2008.

[5] Scheeder, M.R.L. "About the trans-(hi)story: how did trans fatty acids enter the human food chain”. J Am Oil Chem Soc. 18(2). 133-135. 2007.

[6] Mozaffarian, D., Aro, A. and Willet, W.C. "Health effects of trans-fatty acids: experimental and observational evidence”. Eur $J$ Clin Nutr. 63 (2). S5-S21. 2009.

[7] Dorfman, S.E., Laurent, D., Gounarides, J.S., Li, X., Mullarkey, T.L., Rocheford, E.C., Sari-Sarraf, F., Hirsch, E.A., Hughes, T.E. and Commerford, S.R. "Metabolic Implications of Dietary Transfatty Acids”. Obesity. 56(1). 12-21. 2009.

[8] Karbowska, J. and Kochan, Z. "Trans-fatty acids-effects on coronary heart disease”. Pol Merkur Lekarski. 31(181). 56-59. 2011.

[9] Brouwer, I.A., Wanders, A.J. and Katan, M.B. “Trans fatty acids and cardiovascular health: research completed?” Eur J Clin Nutr. 67(5). 541-547. 2013. 
[10] Kiage, J.K., Merrill, P.D., Robinson, C.J., Cao, Y., Malik, T.A., Hundley, B.C., Lao, P., Judd, S.E., Cushman, M., Howard, V.J. and Kabagambe, E.K. "Intake of trans fat and all-cause mortality in the Reasons for Geographical and Racial Differences in Stroke (REGARDS) cohort”. Am J Clin Nutr. 97(5). 1121-1128. 2013.

[11] Chajès, V., Thiébaut, A.C., Rotival, M., Gauthier, E., Maillard, V., Boutron-Ruault, M-C., Joulin, V., Lenoir, G.M. and CavelChapelon, F. "Association between sérum trans-monounsaturated fatty acids breast cancer risk in the E3N study”. Am J Epidemiol. 167(11). 1312-1320. 2008.

[12] Vinikoor, L.C., Millikan, R.C., Satia, J.A., Schroeder, J.C., Martin, C.F., Ibrahim, J.G. and Sandler, R.S. "Trans-Fatty acid consumption and its association with distal colorectal cancer in the North Carolina Colon Cancer Study II”. Cancer Causes Control. 21(1), 171-80. 2010.

[13] Laake, I., Carlsen, M.H., Pedersen, J.I., Weiderpass, E., Selmer, R., Kirkhus, B., Thune, I. and Veierød, M.B. "Intake of trans fatty acids from partially hydrogenated vegetable and fish oils and ruminant fat in relation to cancer risk”. Int J Cancer. 132(6). 1389-1403. 2013.

[14] Mensink, R.P. and Katan, M.B. "Effect of dietary trans fatty acids on high-density and low-density lipoprotein cholesterol levels in healthy subjects”. New Engl J Med. 323. 439-445. 1990.

[15] [FDA]. Food and Drug Administration FOOD FACTS. Talking About Trans Fat What You Need to Know, JMH Education”, New York, 2006. Available at:

http://www.fda.gov/food/resourcesforyou/consumers/ucm079609. htm (Accessed 18 July 2012).

[16] Friesen, R. and Innis, S.M. "Trans fatty acids in human milk in Canada declined with the introduction of trans fat food labeling”. J Nutr. 136(10). 2558-2561. 2006.

[17] Brazil, Ministry of Health. The National Agency of Health Surveillance. RDC Resolution $\mathrm{n}^{\circ} 360$ of December 2003. "Provides technical regulation on nutrition labeling of packaged foods”. Official journal (of) the Federative Republic of Brazil, the Executive Branch, Brasília, DF, 2003.

[18] Brazil, Ministry of Health. The National Agency of Health Surveillance. RDC Resolution $n^{\circ} 54$ of November 2012. "Provides technical regulation on complementary nutrition labeling”. Official journal (of) the Federative Republic of Brazil, the Executive Branch, Brasília, DF, 2012.

[19] [ABIA]. Brazilian Association of Food Industries. "Technical cooperation agreememt between the Ministry of Health and the Brazilian Association of Food Industries”, Brasília, DF, 2007.

[20] Ministry of Health Brazil. "Technical Note: Actions of the Brazilian Government on trans fat”. 2009. Available at: http://nutricao.saude.gov.br/documentos/nota_imprensa_gorduras_ trans.pdf (Accessed 24 September 2012).

[21] Oviedo, K.M.M. "A comparative analysis of regulatory experiences for processed foodstuffs trans fats removal in Brazil, Canada, Denmark and the United States”. Pontifícia Universidade Católica do Rio de Janeiro, Master’s Dissertation, 141 p., 2010.

[22] [PAHO/WHO]. Pan American Health Organization/World Health Organization. "Trans Fat Free Americas (TFFA), Conclusions and Recommendations”, Regional Office at the WHO, Washington, D.C., 2007.

[23] Chiara, V.L., Sichieri, R. and Carvalho, T.S.F. "Trans fatty acids of some foods consumed in Rio de Janeiro, Brazil”. Rev Nutr. 16(2). 227-233. 2003.

[24] Gagliardi, A.C.M., Mancini Filho, J. and Santos, R.D. "Nutritional profile of foods with zero trans fatty acids claim”. Rev Ass Med Bras. 55(1). 50-53. 2009.

[25] Camp, D.V., Hooker, N.H. and Lin, C-TJ. "Changes in fat contents of US snack foods in response to mandatory trans fat labelling”. Public Health Nutr. 15(6). 1130-1137. 2012.

[26] [IBGE]. Brazilian Institute of Geography and Statistics. "National Household Budget Survey 2008-2009: Household Food Acquisition per capita”, Rio de Janeiro, RJ, 2010. Available at: <http://www.ibge.gov.br/home/estatistica/populacao/condicaodevi da/pof/2008_2009_aquisicao/pof20082009_aquisicao.pdf (Accessed 1 July 2011).

[27] [USDA]. United States Department of Agriculture. Economic Research Service. "Dietary Assessment of Major trends in US Food consumption, 1970-2005”. 2010. Available at: http://www.ers.usda.gov/Publications/EIB33/EIB33_Reportsumm ary.pdf (Accessed 23 September 2010).
[28] [AOAC]. Association of Official Analytical Chemists. "Official Methods of Analysis of AOAC”, 18 ed., AOAC International, Gaithersburg, 2005.

[29] Folch, J., Less, M. and Stanley, S. "A simple method for the isolation and purification of total lipids from animal tissues”. $J$ Biol Chem. 226(1). 497-509. 1957.

[30] Hartman, L. and Lago, B.C. "A Rapid Preparation of Fatty Acids Methyl Esters From Lipids”. Laboratory Practice. 22(6). 475-476. 1973.

[31] Kodali, D.R. Trans fats - Chemistry, Occurrence, Functional Need in Foods and Potential Solutions, AOCS Press, Champaign, Illinois, 2005, 150p.

[32] Norhayati, M., Azrina, A., Norhaizan, M.E. and Muhammad Rizal R. "Trans fatty acids content of biscuits commercially available in Malaysian Market and comparison with other countries”. Inter Food Res J. 18(3). 1097-1103. 2011.

[33] Martin, C.A., Carapelli, R., Visantainer, J.V., Matsushita, M. and Souza, N.E. "Trans fatty acid content of Brazilian biscuits". Food Chem. 93(3). 445-448. 2005.

[34] Huang, Z., Wang, B., Pace, R.D. and Oh, J-H. "Trans Fatty Acid Content of Selected Foods in an African-American Community”. $J$ Food Sci. 71(6). C322-327. 2006.

[35] Meremäe, K., Roasto, M., Kuusik, S., Ots, M. and Henno, M. "Trans fatty acid contents in selected dietary fats in the Estonian Market”. J Food Sci. 77(8). T163-168. 2012.

[36] Norum, K.R. “Dietary Fat and Blood Lipids”. Nutr Rev. 50(4). 30 37. 1992.

[37] Jakobsen, M.U., Overvad, K., Dyerberg, J., Schroll, M. and Heitmann, B.L. "Dietary fat and risk of coronary heart disease: possible effect modification by gender and age”. Am J Epidemiol. 160(2). 141-149. 2004.

[38] Tarrani-Trani, M.T., Phillips, K.M., Lemar, L.E. and Holden, J.M. "New and existing oils and fats used in products with reduced trans-fatty acid content”. J Am Diet Assoc. 106. 867-880. 2006.

[39] Skeaff, C.M. "Feasibility of recommending certain replacement or alternative fats”. Eur J Clin Nutr. 63(2). S34-S49. 2009.

[40] McCarthy, M. "US moves to ban trans fats". BMJ. 347:f6749. 2013.

[41] Brownell, K.D. and Pomeranz, J.L. "The Trans-Fat Ban - Food Regulation and Long-Term Health”. N Engl J Med. 370(19). 1773-1775. 2014.

[42] Willet, W. "The case for banning trans fats". Scientific American. 310(13). 2014. Available at: http://www.scientificamerican.com/article/scientific-case-forbanning-trans-fats/ (Accessed 14 July 2014).

[43] [WHO]. World Health Organization. United Nations. SIXTYSIXTH WORLD HEALTH ASSEMBLY. "Draft action plan for the prevention and control of noncommunicable diseases 20132020”. 2013 Available at: http://www.who.int/nmh/publications/ncd_action_plan2013.pdf. (Accessed 24 June 2013).

[44] Brazil, Ministry of Health. Department of Health Care. General Coordination of Food and Nutrition Policy. "Guidelines for the Brazilian Population”. 2005. Available at: http://dtr2001.saude.gov.br/editora/produtos/livros/pdf/05_1109_ M.pdf (Accessed 22 April 2014).

[45] [WHO]. World Health Organization. United Nations. WHO. "Global Strategy on Diet, Physical Activity and Health: list of all documents and publications, Fifty-seventh World Health Assembly”. A57/9, 17 abr. 2004. Available at: http://www.who.int/dietphysicalactivity/strategy/eb11344/strategy _english_web.pdf?ua=1 (Accessed 23 June 2011).

[46] Downs, S.M., Thow, A.M. and Leeder, S.R. "The effectiveness of policies for reducing dietary trans fat: a systematic review of the evidence”. Bull World Health Organ. 91. 262-269H. 2013.

[47] Silveira, B.M., Kliemann, N., Silva, D.P., Colussi, C.F. and Proença, R.P.C. "Availability and Price of Food Products with and without Trans Fatty Acids in Food Stores around Elementary Schools in Low- and Medium-Income Neighborhoods”. Ecol Food Nutr. 52(1). 63-75. 2013.

[48] Galdino, T.P., Antunes, A.R., Lamas, R.C., Zingano, M.A., Cruzat, V.F., Coutinho, V.F. and Chagas, P. "Filled cookies: the cheaper the higher trans fat content?” Scientia Medica. 20(4). 270-276. 2010.

[49] Drewnoswski, A. and Darmon, N. "The economics of obesity: dietary energy density and energy cost”. Am J Clin Nutr. 8(1). 265S-273S. 2005. 
[50] Donkin, A.J.M., Dowler, E.A., Stevenson, S.J. and Turner, S.A. "Mapping access to food in a deprived area: the development of price and availability indices". Public Health Nutr. 3(1), 31-38. 2000.

[51] Drewnoswski, A. "Obesity and the Food Environment Dietary Energy Density and Diet Costs”. Am J Prev Med. 27(3).154-162. 2004.

[52] Brazil, Ministry of Health. The National Agency of Health Surveillance. RDC Resolution $\mathrm{n}^{\circ} 359$ of December 2003. "Provides technical regulation of packaged food servings for purposes of nutrition labeling”. Official journal (of) the Federative Republic of Brazil, the Executive Branch, Brasília, DF, 2003.

[53] Aued-Pimentel, A., Silva, S.A., Kus, M.M.M., Caruso, M.S.F. and Zenebon, O. "Evaluation of total fat, saturated and trans fatty acids in foodstuffs with the claim trans free". Braz J Food Technol. 7(1). 51-57. 2009.

[54] Proença, R.P.C. and Silveira, B.M. "Intake recommendations and labeling of trans fat in processed foods in Brazil: analysis of official documents”. Rev Saúde Pública. 46(5). 923-928. 2012.
[55] Brazil, Federative Republic. "Law 8.078”. Federal Planalto, Brasília, DF, 1990.

[56] Silveira, B.M., Gonzalez-Chica, D.A. and Proença, R.P.C. "Reporting of trans-fat on labels of Brazilian food products". Public Health Nutr. 16(12). 2146-2153. 2013.

[57] [DNC]. Danish Veterinary and Food Administration. "Executive Order $\mathrm{n}^{\circ} 160$ of 11 March 2003 on the content of Trans Fatty Acids in Oils and Fats". 2003. Available at: http://www.fujioileurope.com/products/Functionalities/Docs/DKle gislationTFA_engl.pdf. (Accessed 12 May 2011).

[58] Howlett, E., Burton, S. and Kozup, J. "How Modification of the Nutrition Facts Panel Influences Consumers at Risk for Heart Disease: The Case of Trans Fat”. J Public Policy \& Marketing. 27(1), 83-97. 2008.

[59] Richter, E.K., Shawish, K.A., Scheeder, M.R.L. and Colomban, P.C. "Trans fatty acid content of selected Swiss foods: The Trans Swiss Pilot study”. J Food Comp Anal. 22(5). 479-484. 2009.

[60] Kuhnt, K., Baehr, M., Rohrer, C. and Jahreis, G. "Trans fatty acid isomers and the trans-9/trans-11 index in fat containing foods". Eur J Lipid Sci Tech. 113(10). 1281-1292. 2011. 